\title{
English Politeness Markers and Translation Ideology
}

\author{
Ina Sukaesih ${ }^{1}$, M.R. Nababan ${ }^{2}$, Riyadi Santosa ${ }^{3}$, Djatmika $^{4}$ \\ \{ sukaesihina124@gmail.com ${ }^{1}$, amantaradja@yahoo.com ${ }^{2}$, \\ riyadisantosa1960@gmail.com ${ }^{3}$, djatmika@staff.uns.ac.id $\left.{ }^{4}\right\}$
}

Universitas Sebelas Maret, Indonesia ${ }^{1,2,3,4}$

\begin{abstract}
This article discusses politeness markers in English found in King Solomon's Mines novel and their translated version in Pependeman Nabi Sulaeman. This presents the result of an investigation on the politeness markers and the translation techniques used in meaning transfer. The main focus is to find out the translation ideology of the translator in this translating the English politeness markers from the novel. In analyzing the politeness markers, the taxonomy of the politeness structure of the House and Kasper added by terms of address is applied, while the translation techniques proposed by Molina \& Albir are used to find out the translation techniques exercised by the translator. From 645 politeness markers, terms of address and downtoners are most frequently used by $45 \%$ and $22 \%$ respectively. While the most dominating translation techniques exercised are a deletion, established equivalence and variation with the percentages of 53,16 , and 15 . It can be summed up that in the novel honorific markers are used to show politeness, while from the translation techniques used, it can be seen that the translator is keen on implementing the domestication translation ideology.
\end{abstract}

Keywords: politeness markers, English, Sundanese, translation technique, translation ideology

\section{Introduction}

Researches discussing politeness markers and strategies have been carried out [1] [2]. The former talks about the application of the topic, while the latter focuses on the theory. While researches on honorific translation have been carried out by several researchers [3] [4] [5] [6] [7]. The studies conducted discuss political politeness strategies in certain language functions that are used both in the source language (SL) and the target language (TT). Researches on the translation of honorific markers that have been carried out involve the target language of English, other European languages, Indonesian and Javanese.

At present, there has never been any research that involves translating from the source language of English to the target language of Sundanese. Hence we cannot underestimate Sundanese, one of the important ethnic languages in Indonesia, has its interlocutors of not less than 30 million and has contributed to the enrichment of Indonesian as the national language. Furthermore, Sundanese people nowadays are very productive and give attention to the development of the language which is proved by the annual appreciation award 'Rancage' rendered to scholars for several language contribution categorizations, one of them is a literary work.

English is a language categorized as coming from a low - context culture while Sundanese language is originating from high-context culture. Characteristics of language derived from high-context culture are that the meaning of expressions is generally not determined by the literal meaning of the word, but is determined by the context. While the 
characteristics of languages coming from a low - context culture show that the meaning of words contained in words themselves, and the context does not play a significant role in giving meaning to the expression.

Languages classified as high-context culture ones are languages from Asia and other regions of the globe, including Afghans, African, Chinese, Indian, Indonesian, Turkish. While those included in the low-context culture among others are Australian, Dutch, English, German, Israeli, United States.

Seeing the origins of English and Sundanese coming from a different culture, this research conducted on English honorific markers translation into Sundanese. The research materials used for this subject of translating honorific markers from English into Sundanese are Henry Rider Haggards literary work entitled 'King Solomon's Mines' (Haggards) written at the beginning of the $19^{\text {th }}$ century and its translation in Sundanese by Moh. Ambri, with the title of "Pependeman Nabi Sulaeman" [8].The study examines the honorific markers contained in the Target Text (TT) and the translation techniques used that will converge on the conclusion of the translation ideology adopted by the translator.

Juliane House and Kasper identify eleven English honorific markers, namely: politeness markers, play-downs, consultative devices, hedges, understaters, downtoners, committers, forewarnings, hesitators, scope-staters, agent avoiders. These markers are added by one more honorific marker proposed by Wards, i.e., Terms of address. Therefore those twelve honorific markers are used to frame the research conducted.

The translation of the honorific markers is examined from the point of view of translation techniques exercised by the translator. And the translation techniques are proposed by Molina \& Albir who identify 18 translation techniques. These are used for the analysis of the comprehensive techniques they proposed, as they also have mentioned that the translation techniques have covered those from other translation renowned scholars. These can relatively cater to translation problems facing translators.

An ideology of translation refers to the understanding adopted by a person based on the principles s/he believes. Ideology is the idea, point of view, and the principle, the truth the community believes. In translation, the ideology referred to is the belief of a translator in translating. There are two translation ideologies, namely foreignization and domestication.

Foreignization considers translation as a media to transfer all aspects of the source text, such as cultural elements, norms, habits. While domestication prioritizes the other side, the target readers so that what a translator does will focus on the interest of the readers. These choices affect the translation methods and techniques a translator may use.

Translation methods are divided into two categories which obviously separate the two languages involved in the translation: source language and target language. Newmark divides the two using $\mathrm{V}$ diagram showing the two divisions of translation methods under Source Language (SL) emphasis and Target Language (TL) emphasis.

The methods under SL category cover word-for-word, Literal, Faithful and Semantic, while the ones under TL include Adaptation, Free, Idiomatic and Communicative. Therefore, we may come to a conclusion on the translation ideology a translator uses by studying the methods and techniques of translation they apply.

\section{Methodology}

Honorific markers were reviewed using the taxonomy of politeness structure proposed by Juliane \& Kasper with 11 honorific markers and one category, namely the terms of address [9]. While the translation techniques were measured by the translation techniques proposed by Molina \& Albir [10]. The identified honorific markers were broken down into the eleven types and terms of address. Each marker was examined using translation techniques. By studying 
the trend of the translation techniques exercised by the author, then the translation ideology was revealed.

\section{Result and Discussion}

\subsection{Honorific markers}

The honorific markers referred to are the taxonomy of politeness structure proposed by the House and Kasper in 1981 which included eleven categories, while it could not be ignored that the terms of address [9] were also honorific markers although they still had to consider 'power', 'distance' and ' rank of imposition '. Then the discussion includes both the eleven categories proposed by House and Kasper and also terms of address by Watts. One more reason including terms of address is that the use of the terms of address dominated the honorific markers found in the research document. The following is a table identifying the categories of honorific markers found in the novel "King Solomon's Mines."

\begin{tabular}{|c|l|c|c|}
\hline No & \multicolumn{1}{|c|}{ Honorific Markers } & Total & $\begin{array}{c}\text { Percentage } \\
(\%)\end{array}$ \\
\hline 1 & Address Systems & 299 & 45,79 \\
\hline 2 & Downtoners & 140 & 21,44 \\
\hline 3 & Committers & 78 & 11,94 \\
\hline 4 & Hedges & 78 & 11,94 \\
\hline 5 & Understaters & 15 & 2,297 \\
\hline 6 & Agent Avoiders & 13 & 1,990 \\
\hline 7 & Play-downs & 10 & 1,531 \\
\hline 8 & Hesitators & 8 & 1.225 \\
\hline 9 & Forewarnings & 8 & 1,225 \\
\hline 10 & Politeness Markers & 4 & 0,612 \\
\hline 11 & Consultative Devices & 0 & 0 \\
\hline 12 & Scope-staters & 0 & 0 \\
\hline & Total & 653 & 100 \\
\hline
\end{tabular}

Of the 653 data collected from the research documents, it can be seen the distribution of honorific markers used which are based on the taxonomy of the politeness structure proposed by House and Kasper and the terms of address [9]. Most used honorific markers are the terms of address 299 times; the second most used were down toners 140 times; the third and the fourth were committers and hedges, both were used 78 times. Other types of honorific markers in use range from 15 to 0 , even two, consultative devices and scopestaters are not found in the research documents. 


\subsection{Translation Techniques}

The following is the table showing translation techniques exercised by the translator.

\begin{tabular}{|c|l|c|c|}
\hline No & Translation Techniques & Number of use & Percentage \\
\hline 1 & Deletion & 379 & 54.97 \\
\hline 2 & Established Equivalence & 105 & 15.350 \\
\hline 3 & Variation & 98 & 14.327 \\
\hline 4 & Modulation & 42 & 6.140 \\
\hline 5 & Naturalized Equivalence & 20 & 2,923 \\
\hline 6 & Discursive Creation & 13 & 1,900 \\
\hline 7 & Literal & 9 & 1,315 \\
\hline 8 & Explicitation & 5 & 0,730 \\
\hline 9 & Paraphrase & 4 & 0.584 \\
\hline 10 & Implicitation & 4 & 0.584 \\
\hline 11 & Pure Borrowings & 2 & 0.292 \\
\hline 12 & Adaptation & 1 & 0.146 \\
\hline 13 & Addition & 1 & 0.146 \\
\hline 14 & Reduction & 684 & 0.146 \\
\hline & Total & & $100 \%$ \\
\hline
\end{tabular}

From the table, it can be seen the number of each translation technique used by the translator. The translation technique that is most commonly used is deletion, as many as 379 times from the total 684 translation techniques. While in the second order, established equivalence is used 105 times, and variation in the third order is used 98 times, followed by modulation translation technique 42 times and naturalized borrowings technique 20 times, discursive creation 13 times and literal technique 9 times. The rests are used less than nine times: explicitation technique five times, paraphrase and implicitation techniques four times, pure borrowing technique twice, and adaptation, addition and reduction techniques each one time.

There are some arguments which can explain why the translator uses deletion translation technique. First, he avoided the transfer because of his inability, or he faced difficulties in transferring, and it is his purpose to avoid translating them. In this case, the dominant use of deletion translation technique refers to the assumption that the translator exercised his freedom in using his option to not translating those honorific markers. This may happen when the translator prefers to put his readers' concern as his first priority, so he adapted his work to suit his readers' interest.

The second most used translation technique was established equivalence which was 105 times equals to about $15 \%$. This technique is used to find the closest equivalent meaning of the message to the one in the source text. This technique makes use of target text terminologies which obey the target text language rules and norms. This also proves that the translator tends to put more concerns on the target rather than the source text. This is supported by the $\mathrm{V}$ Translation Methods diagram below stating the tendency of translation methods either to the source text or the target text [11].

\section{SL Emphasis \\ Word-for-word translation \\ Literal Translation \\ Faithful Translation \\ Semantic Translation}

TL Emphasis

Adaptation

Free Translation

Idiomatic Translation

Communicative Translation 
This established equivalence technique is one under communicative translation methods which tend to give more emphasis on the target text. Variation technique is in the third place, its use in the translation amounts to 98 times and equals 14\%. In Sundanese as the target text, there found speech level systems, where there are more than one options of expressions can be used, and this speech level may be used by its interlocutors depending on the context. It is fortunately that speech level gives the translator freedom to choose any expressions which he believes are suitable with the context when the conversation occurs. Again in this instance, looking at the options selected, it is obvious that the translator opts for the target text which again means giving much attention to the readers' interest.

The other two most used translation techniques: naturalized equivalence and discursive creation also tend to put more emphasis on the interest of the readers. Naturalized equivalence which focuses on finding equivalence which is commonly used and accepted and conforming to the rules in target language certainly ease the readers to understand and enjoy reading. Exercising discursive creation technique means that the translator transfer different messages from the ones in the source text which shows us very clearly that the translator, no doubt put his readers' interest in his first priority.

Furthermore, when we refer to the V diagram from Newmark, there are only two translation techniques which tend to support the importance of source text, i.e. Literal and Pure Borrowings. The frequency of those translation techniques is not very significant so that it does not give significant influence on the translation result in terms of translation quality. The others, although they are used less frequently in the translation, such as adaptation and addition, all tend to take the target text as the priority. The translator prioritizes that the readers of the text should be satisfied although the complete content of the source text may be reduced and the translation function as the media of culture transfer may be neglected. It is clear that translation techniques supporting the importance of target text dominate. The translator focused on how the readers are really happy and entertained by the translated text.

\subsection{Translation Ideology}

Translation ideology is determined by a translator in the initial step of the translation process. It may be executed when a translator has read the source text, after knowing the target readers, and any other considerations she or he has. The two translation ideologies, i.e. foreignisation and domestication can be deducted from the translation techniques exercised by the translator. Considering the translation techniques used in translating the English honorific markers found in the novel 'King Solomon's Mines' in its translated version 'Pependeman Nabi Sulaeman', it may be concluded that the translator exercised the domestication translation ideology.

\section{Conclusions}

The use of translation techniques as a medium to transfer messages from source text into a target text has a necessary effect. The use of different translation techniques obviously leads to different translation ideology. And based on the most frequently used of the translation techniques and their explanation, and also the connection with translation theory, it can be concluded that the translation of honorific markers in the novel adopted the domestication translation ideology.

\section{References}

[1] Minoo, S. A. Politeness markers in English for business purposes textbook (2013).

[2] Leech, G., \& Larina, T. Politeness west and East. Вестник РУДН, серия Лингвистика, 9-34 (2014). 
[3] Ardi, H., Nababan, M., Djatmika, \& Santosa, R. Characters' Politeness Strategies in Giving Command: Should translators keep them? The Southeast Asian Journal of English Language Studies, 24(2), 181-193 (2018)

[4] Solum, K. (Im)politeness between copy-editors and from different islands? translators: Working Scandinavian Journal of Intercultural Theory and Practice, 4(1), 1-23 (2017).

[5] Kumari, N. A Survey of Studies on Sociopragmatic Use of Linguistic Politeness with special focus on Hindi and Japanese. International Journal of Languages, Literature, and Linguistics, 2(4), 267 274 (2015).

[6] Ambuyo, A. (ms). Face Threatening acts and standing orders: 'Politeness' or 'politics' in the question time discussion of the Kenyan Parliament. International Journal of Humanities and Social Science, 9(1), 209-218 (2011).

[7] Zaman, M. N., Nababan, R. M., \& Djatmika. Translation Study on Greetings and Verbs in Accommodating Honorific Expressions of Okky Mandasari Novels. Jurnal Pendidikan: Teori, Penelitian Pengembangan, 528-537 (2018).

[8] Ambri, M. Pependeman Nabi Sulaeman. Bandung: C.V. Duar (1966).

[9] Watts, R. Politeness. Cambridge: Cambridge University Press (2003).

[10] Molina, \& Albir. Translation Techniques Revisited: A dynamic and functional Approach. Meta, 4 (2002).

[11] Newmark, P. A Textbook of Translation. New York: Tice Hall Press (1988). 